\title{
Role of L1 in L2 Acquisition According to Contrastive Analysis Hypothesis and Error Analysis
}

\author{
Mai Thi Phuong Thao \\ English for Specific Purposes' Section, Danang University of Economics \\ 71 Ngu Hanh Son, Da Nang, Vietnam
}

\begin{abstract}
In the changed context of a globalized world where English language continues to grow as a second or third language in many parts of the world, acquiring two primary languages simultaneously gains an increasing popularity. In this case, reviewing the influence of L1 on second language acquisition, i.e. language transfer, is of great importance. Though the theory of language transfer has experienced a long time of ups and downs since 1940 s, up to now, it is still a central issue in applied linguistic, second language acquisition and language learning. Much of the history of this central concept has been tied in with the varying theoretical perspectives on SLA. The acceptance and/or rejection of language transfer as a viable concept has been related to the acceptance or rejection of the specific theory with which it has been associated. The article aims to compare and contrast views of the role of L1 in L2 acquisition according to Contrastive Analysis Hypothesis and Error Analysis approaches to reinvestigate how the views of L1's contributions to SLA changed in the early approaches.
\end{abstract}

Keywords: Contrastive Analysis Hypothesis, Error Analysis, L1, L2, language transfer

DOI: $10.7176 / \mathrm{JEP} / 11-2-11$

Publication date: January $31^{\text {st }} 2020$

\section{Introduction}

The role of the native language has had a rocky history in second language acquisition research and practice (Gass and Selinker, 2008). Various terminologies emerging can show how complicated the phenomenon is in the course of second language acquisition (SLA). These terms are language transfer, linguistic inference, the role of mother tongue, native language influence and language mixing (Odlin, 2005). Each term tends to trigger a controversial debate on the sense it conveys and on the linguistic and psychological base it roots.

Hence, "no single term is entirely satisfactory" (Odlin, 2005, p.436). For example, the notions of 'interference' and 'transfer' seem to be closely associated with behaviourist theories of L2 learning (Ellis, 1994). Thus, the demis of the behaviourism led to the rejection of these terminologies in SLA for a period of time. The prevailing mentalist theory witnesses the emergence of the new terms relating to the native language influence such as avoidance, borrowing and so on. Thus, there needs to have a superordinate terms that is theory-neutral, "allowing one to subsume under one heading such phenomena as 'transfer', 'interference', 'avoidance' 'borrowing' and L2-related aspects of language loss and thus permitting discussion of the similarities and differences between these phenomena" (Smith \& Kellerman, 1986, cited in Ellis, 1994). Cross-linguistic influence is suggested by Smith and Kellerman in such a situation.

Meanwhile, with the re-examination and recognition of the role of L1 in cognitive perspective, the term 'transfer' has been used by many scholars without restriction. Far removed from the original use of the term in behaviourist theories of language learning, 'transfer' is now viewed in a broader perspective including most of the cross-linguistic phenomena. This can be seen in the 'working definition' by Odlin (1989): "Transfer is the influence resulting from the similarities and differences between the target language and any other language that has been previously (and perhaps imperfectly) acquired" (p.27).

In general, much of the history of the L1 influence has been tied in with the varying theoretical perspectives on SLA. The acceptance and rejection of this phenomenon has been related to the acceptance or rejection of the specific theory with which it has been associated.

\section{Contrastive Analysis}

In order to identify the areas of difficulty, a procedure called Contrastive Analysis was developed. This was founded on the belief that it was possible, by establishing the linguistic differences between the learner's L1 and L2, to predict what problems the learner of a particular L2 would face. This resulted in a list of features of the L2 which were presumed to constitute the problem areas and which were given focal attention in the teaching syllabus. 2.1. Contrastive Analysis Hypothesis

Contrastive Analysis originated from the pedagogic purpose (Ellis, 1985; Larse-Freeman \& Long, 1991). Following Fries's statement that the most efficient teaching materials should be based on the careful comparison between the learner's native language and the language to be learned (Larse-Freeman \& Long, 1991), Lado (1957, cited in Ellis, 1985) also claimed that the teachers who made this comparison would know better the real problems of their students and thus, would increase the efficiency in L2 teaching and testing (Saville-Troike, 2006). 
Hence, according to Gass and Selinker (1994), Contrastive Analysis arose to "determine the potential errors for the ultimate purpose of isolating what needs to be learned and what does not need to be learned in a secondlanguage-learning situation" (p.96). With regard to this hypothesis, L2 learners' productive and receptive skills are influenced by their L1 patterns and that similarities and differences between L1 and L2 are important predictors of ease and difficulty of L2 learning (Karim \& Nassaji, 2013). In this case, when there were similarities between the two languages, positive transfer would occur. However, when there were differences between them, negative transfer, or interference would emerge.

There are two differentiated versions developed within the CAH: CA apriori approach and aposteriori approach. The former, also called the predictive or the strong view, aims to make predictions about the learning difficulties based on a 'point by point' comparison in terms of phonology, morphology, syntax or other subsystem between the two languages (Schachter, 1974). In the meanwhile, the later starts with an analysis of learners' recurring errors in a particular construction, then bases on the differences between the compatible native language (NL)-the target language (TL)'s constructions to account for those errors (Schachter, 1974; Gass \& Selinker, 1994). The later approach is also called the weak or explanatory view and is also considered, according to Schachter (1974), a subcomponent of Error Analysis, which will be discussed later in this article.

\subsection{Language acquisition as habit formation}

To understand why CAH were widely accepted as the mainstream view of language learning at that time (or the language transfer phenomenon were widely accepted), it is important to understand the psychological and linguistic theories where CAH rooted: Structuralism and Behaviorism.

Following the notions in structuralist linguistics, CA focuses on describing and comparing the surface forms of both L1 and L2 language system, generally contrasting phonology, morphology, syntax, lexicon and discourse (Saville-Troike, 2006). This was clearly asserted by Fries, who was an influential figure in applying the structural linguistics to L2 teaching: "In learning a new language, ... the chief problem is not at first that of learning vocabulary items. It is, first, the mastery of the sound system. It is, second, the mastery of the features of arrangement that constitute the structure of the language" (1945, cited in Saville-Troike, 2006).

In terms of behaviourist psychology, language learning is seen as the formation of habits (Ellis, 1985; Ellis, 1990; Gass \& Selinker, 1994; Skinner, 1957, cited in Mitchell, Myles \& Marsden, 2013). It stems from behaviourist psychologists such as Watson and Skinner, who associated the notions of stimulus - response reinforcement. In their theory, human beings are exposed to numerous stimuli in their environment, then response to them. If one response is repeated time after time under the same stimulus, i.e. there is reinforcement, habit will be established and become stronger.

Thus, habit-formation theory was applied to the theories of learning, both in L1 and L2 acquisition in the 1950s and 1960s (Ellis, 1985). From this perspective, learning a first language means learning a set of new habits. Second language learning, then, involves replacing the habits of the native language in order to acquire the new habits of the target language. This provides a theoretical account of how learner's L1 interfere with the process of SLA, either helping or inhibiting it (Ellis, 1985; Mitchell, Myles \& Marsden, 2013).

As a consequence, the notion of interference became central in behaviourist accounts of SLA (Ellis, 1985). As L1 gets in the way of L2 learning process, it was, then, seen as the major cause for lack of success in acquiring L2. Lee (1968, cited in Ellis, 1985) reasoned the prime or even the sole cause for the difficulties and errors in L2 coming from interference of the learner's native language. Also, the significance in the role of L1 was once best expressed by Lado (1957, cited in Larsen-Freeman \& Long, 1991): "Individuals tend to transfer the forms and meanings of their native language and culture to the foreign language and culture - both productively when attempting to speak the language and to act in the culture receptively when attempting to grasp and understand the language and the culture as practised by natives." (p.1)

Although Lado (1957, cited in Larsen-Freeman \& Long, 1991) caveat that the problems predicted through the comparison of L1 and L2 must be considered hypothetical ones until there are some valid check from the actual performance of learners. However, under the strong influence of the psychological and linguistics theories on which CAH based, CAH still took a dominant role in during 1950s and 1960s despite the insufficient final validation. The $\mathrm{CAH}$ demise, thereafter, could not be avoided when there were a plate of empirical tests based on Chomskyan linguistics which went against the Behaviourism theory of Skinner. This will be discussed in the next section.

\subsection{Contrastive Analysis being criticized}

In the early 1970s, CAH was under attack when predictions made by Contrastive Analysis did not seem to borne out in practice. Besides, criticism involving the theory was also made in the feasibility of comparing languages and methodology of contrastive analysis. In addition, there was doubt about the relevant application of contrastive analysis in the language teaching as it was the pedagogical purpose from which CAH rooted as already mentioned above (Ellis, 1985). 


\subsubsection{Theoretical}

If the heyday of Behaviourism theory gave CAH the important position in SLA during the 1950s and 1960s, it was the attack against this theory that led CAH to its demise in the 1970s. The attack was given impetus by Chomsky's (1959, cited in Mitchell, Myles and Marsen, 2013) in A review of B.F. Skinner verbal behavior.

Chomsky's attack on behaviorism struck at the psychological basis of the theories of language learning. He fiercely criticized Skinner's comparison between animal behaviour in laboratory condition and human behaviour in natural condition. He said what Skinner did could show nothing about how human being learn a language in natural condition. He and some other scholars believed that stimulus and response could not be applied to language learning or they would be considered vacuous as it was not possible to tell what constituted the stimulus for a given speaker response (Ellis, 1985).

In Chomsky's argument, children are born with an innate capacity to acquire language, as they do not merely imitate the language around them, but routinely create new sentences and rules (Chomsky, 1959, cited in Mitchell \& Myles, 1998; Mitchell, Myles \& Marsen, 2013). This following example can illustrate what Chomsky said:

Child: I don't see no trees.

Mother: I don't see any trees. Not no trees, any trees.

Child: No any trees. No any trees.

Mother: I don't see any trees.

(Cazden, 1972, cited in Gass \& Selinker, 1994, p.92)

In this example, the child does not passively copy what his mother says and corrects. Instead, he creates the rule by himself, trying to make sense of the language they are exposed to. They construct the rules themselves. Language, therefore, "came to be seen in terms of structured rules instead of habits. Learning was seen not as imitation but as active rule formation" (Gass \& Selinker, 1994). With respect to this perspective, language acquisition is not much affected by outside factors. Thus, that period of time saw 'a shift from structural linguistics, which was based on the description of surface structure of a large corpus of language to generative linguistics that emphasized the rule-governed and creative nature of human language' (Mitchell \& Myles, 2004, p.32)

Based on Chomskyan approach, such SLA researchers as Krashen (1984, cited in Gass \& Selinker, 1994) and Dulay and Burt (1973) claimed that L2 acquisition has a similar process as child L1 acquisition (i.e. L2 = L1 acquisition hypothesis). Therefore, L1 influence plays no role here as learners can gradually create the rules of the language until "the mismatch between what they are exposed to and what they produce is resolved" (Gass \& Selinker, 1994, p.127). Furthermore, they claimed that L2 and L1 learner errors are very similar (Karim, Nassaji, 2013). Most of the errors, according to them, come from developmental, not transfer errors. This mentalist or minimalist perspective downplayed the role and function of L1 remarkably, thus leading to the demise in its pedagogical role.

The second theoretical criticism involves the notion of difficulty and errors. Do differences lead to difficulties and do difficulties lead to learner's errors as hypothesized by the CAH (which would present that differences were equated with difficulties and difficulties were equated with errors)? This is proved not the case.

As for the first equation, difference is a linguistics concept, whereas difficulty is a psychological concept. Thus, as what Ellis (1985) said, it is hardly possible for the level of learning difficulty can be inferred directly from the degree of difference between two languages. Meanwhile, in the example from Kellerman (1987, cited in Gass \& Selinker, 1994, p.82), a student wrote "But in that moment it was 6:00". The student insistently said that she was confused about the usage of past simple or past perfect tense while her error was clearly the unsuitable preposition 'in'. Herein, the overt error did not prove that she was struggling with it. The difficulty, meanwhile, would lie in other area (the tense). So, difficulty cannot be equated with error (Gass \& Selinker, 1994; Ellis, 1985). Another problem concerns the linguistic basis of comparing two languages. According to Ellis (1985), the normal practice in CA was to "compare the formal features of translationally paired sentences" (p.31). This seems to be a complex issue since a fully contrastive analysis needs to compare pragmatic as well as linguistic aspects of the two language systems. For example, an English speaker learning Italian would find the translation equivalent of the verb 'to know' difficult, because there are two possibilities in Italian language: sapere (meaning to know a fact, to have knowledge of something, or to know how to do something), and conoscere (meaning to be familiar or acquainted with something). The complexity of doing cross-linguistic comparison is clearly shown in the hierarchy of difficulty by the work of Stockwell, Bowen, and Martin (1965, cited in Gass \& Selinker, 1994) who dichotomized the results of language comparison into ease-difficulty continuum and thus, created a learning hierarchy.

2.3.2 Empirical

The predictive validity of many contrastive analyses seemed called into question. Firstly, CAH would predict that where there are differences, errors would be bi-directional (Lightbown \& Spada, 2006). However, Helmut Zobl (1980, cited in Gass \& Selinker, 1994), for example presented several examples that this is not always the case. Take the sentence structures in English and French as an example: In English, object pronoun follows the verb ( $I$ see them) while in French, object pronoun precedes the verb (Je les vois $-I$ them see $=$ I see them). Thus, the CAH 
would predict that an English learner of French might make such an error: Je vois les and that a French learner of English might say "I them see". In fact, English learners of French tend to make more predicted errors than French learners of English. Within a theory based on the transference of L1 form, this could not be explained why it happens in one direction, but not in the conversed one.

Secondly, following the mentalist perspective and based on the Creative Construction Hypothesis, Dulay and Burt (1973) sought to challenge the importance of the L1 and emphasize the contribution of universality of language learning by conducting some empirical tests which dismissed the pervasiveness of interference (Ellis, 1994). They conducted the speech study on Spanish children learning English and produced a quite surprising result with only 3 per cent of identified interference errors. Other types of errors were interference-like errors (Those reflect native language structure and are not found in first language acquisition); first language developmental errors (i.e. those do not reflect native language structure but are found in first language acquisition); ambiguous errors (i.e those that cannot be categorized as either interference-like or developmental); unique errors (i.e those that do not reflect first language structure and also are not found in first language acquisition data) (Ellis, 1985, p.28).

Thus, with only 3 per cent of learner's errors resulted from interference, the comparison between the two language systems in contrastive analysis was of little use to predict or explain the SLA process and the role of transfer fell into disfavour. Although this research result seemed to be far distinct from those of other researchers' on the various studies of L2 English grammar (e.g. Grauberg (1971) with 36\% of interference errors, George (1972) with 33\%, Tran-Thi-Chau with 51\%, Mukattash with 23\%, Flick (1980) with 31\% and Lott (1983) with $50 \%)($ Ellis, 1985), it was a really harsh attack on the $\mathrm{CAH}$ at that time.

1.3.3 Practical considerations

The final set of criticism concerns whether contrastive analysis is of any practical worth to language teachers (Ellis, 1985). As already mentioned, contrastive analysis aims to predict and describe the problem areas of L2 learners, based on which the preparation of pedagogical materials would be made (Saville-Troike, 2006). According to $\mathrm{CAH}$, most learners' errors come from L1 interference. However, a great many empirical tests have shown that this is not the case.

Besides, the CA was conducted in the need to avoid errors (Ellis, 1990) as errors were seen as 'sins' and needed to be wiped out. However, errors are now seen as a positive aspect, which will be discussed later. The necessity to do a contrastive analysis was, therefore, called into question at the time.

\section{Error Analysis}

The fact that CAH did not live up to its expectations and many studies showed convincingly that the majority of errors could not be traced back to the L1 allowed the Error Analysis to emerge, marking the shift of researchers and teachers' interests into the language produced by learners, instead of the target language or the native language (Mitchell \& Myles, 1998). It describes and analyses the actual performance errors of learners and focuses on learner's creative ability to construct the language (Saville-Troike, 2006). Although CA was concerned with errors, the emphasis tended to be on predictions, not descriptions, of learner behaviour as EA did (Byram, 2004).

\subsection{Strong and weak versions of the CAH versus Error Analysis}

Error Analysis is similar to the weak version of Contrastive Analysis in a way that both start from the learner production data (Gass \& Selinker, 1994; Bot, Lowie \& Verspoor, 2005). However, while the weak version of CAH is useful in explaining the learners' errors by pointing to the similarities and differences between the NL and the TL, EA aims to compare the TL to the actual performance to see what systematic error patterns emerge (Byram, 2004; Gass \& Selinker, 1994; Larsen-Freeman \& Long, 1991)

In addition, unlike the strong version of CAH where the prediction that most, even all of the errors would result from the L1 interference "were shown to be unfounded" (Mitchell \& Myles, 1998, p.30), in Error Analysis hypothesis, though the role of L1 could not be denied and could be observed in the language performance in many studies, it recognizes non-interference errors in the course of second language acquisition besides the L1 transfer errors. What's more, there are some areas, where the L1 should have been prevented errors, not always being "error-free" (Mitchell \& Myles, 1998, p.30). Thus, it is the degree of emphasis on L1 interference that differentiates CA from EA (Byram, 2004).

\subsection{Language acquisition as rule formation}

As Behaviourism which saw language acquisition as a product of habit formation could not be the good foundation for the second language acquisition to account for any more, there was a shift to the Mentalist theory so that researchers and teachers could have a more adequate basis to explain the learner production data. In this theory, the surface comparisons on forms and patterns between two languages in $\mathrm{CAH}$ were replaced by the concern for the underlying rules in which the innate capacity of the language learner was more focused than the external influences (Saville-Troike, 2006). 
Error Analysis was clearly influenced by the dominant linguistic thought of the time (Bot, Lowie \& Verspoor, 2005), which was inspired by Chomsky's theory of language acquisition. Chomsky posited a theory in which "humans were thought to possess a certain innate predisposition to induce the rules of the target language from the input to which they were exposed" (Larsen-Freeman, 1991, p.57). Thus, they can understand and create the sentences they have never heard before and do not merely imitate what others say as what CAH assumed. They apply these underlying rules to create their own utterances (Saville-Troike, 2006; Larsen-Freeman, 1991). In second language acquisition, based on the mismatch between the L2 and L1, the learners, then, would gradually modify their own utterances to increasingly conform to the target form. Language, therefore, came to be understood as rule-governed behaviour (Saville-Troike, 2006).

\subsection{Interlingual versus intralingual errors}

As CA only attributed errors to the native language, EA provides a broader range of possible ways of explaining the errors. That is errors can be either interlingual or intralingual. The former was traced to the L1 interference while latter, also called as developmental errors, was independent of the L1, often representing incomplete learning of L2 rules such as overgeneralization (Richards, 1971), simplification (George, 1972), communication-based (Selinker, 1972), induced errors (Stenson, 1974) (cf. Larsen-Freeman \& Long, 1991). For example, Richards collected samples of errors in L2 English production data by learners of different L1s and identified common errors (Richards, 1984, cited in Byram, 2004). He found that most of the errors did not come from L1 influence. Dulay and Burt (1973, cited in Ellis, 1994) also assumed that around 80 per cent of errors could be explained without the reference to $\mathrm{L} 1$ interference.

Nevertheless, unlike CAH in which errors are something that needs to be avoided at all costs; errors, according to Corder (1967), are not necessarily bad habits that need to be eradicated but something indicative of some stage of the learning processes. He assumed that making errors is important because it is a way the learner tests his hypothesis about the nature of the language he is learning (Corder, 1967, Saville-Troike, 2006). Errors, then, are an indication that the learner is "exploring the new system rather than just experiences the interference from old habits" (Saville-Troike, 2006, p.39). The knowledge that learner acquires at that time is seen as transitional competence on the course of second language acquisition development. This is linked closely to the interlanguage concept of Selinker (1972).

\subsection{Error analysis being criticized}

As a replacement of CA, EA was still proved to be "an imperfect research tool" (Ellis, 1994, p. 19, cited in Byram, 2004). One of the major criticisms of EA was that it totally relies on errors, not considering the non-errors. Thus, it cannot get the "entire picture of a learner's behaviour (Gass \& Selinker, 1994, p. 104; Larsen-Freeman, 1991; Byram, 2004).

Besides, it fails to account for all the areas of target language in which learners have difficulties (LarsenFreeman \& Long, 1991). Take the study by Schachter (1974) in Error in Error Analysis as an example: Chinese and Japanese speakers were found to make fewer errors in English relative clause production ( 9 and 5 errors respectively) than Persian and Arabic speakers (43 and 31 respectively). However, it does not mean that Chinese and Japanese speakers are more competent users of relative clauses than the other two language users. In fact, overall they produced half as many relative clauses as did the Persian and Arabic. As far as the Chinese and Japanese languages are concerned, they have different structures in terms of relative clauses from the English language than the other two. Thus, it is reasonable to assume that they avoided using them for fear that they would make errors on it. Hence, the L1 structure is an important base on accounting for this Avoidance phenomenon but EA fails to recognize it.

Another problem concerning EA is that it is difficult to identify the types of errors. In the example study by Schachter and Celce-Murcia (1971, cited in Gass \& Selinker, 1994), the sentence "There are so many Taiwan people live around the lake" gave the first impression of a relative clause's error lacking the relative marker (who). However, this can be explained with regard to the native language constructed in a topic-comment style. Thus, with the either-or perspective in which each error is of one type or another, EA fails to account for the errors that may be influenced simultaneously by various sources (Gass \& Selinker, 1994)

To summarize, although EA moves a step beyond the CA in its recognition that leaners are more active in their learning procedures rather than just passive imitators from the native language's structures, it fails to "serve as a primary mode of SLA analysis" (Larsen-Freeman \& Long, 1991) due to its contribution to only a partial picture of the learner's learning process. Thus, it may be more effective when being incorporated into overall performance analysis, which considers the whole picture of the learner language performance (Byram, 2004).

\section{Conclusion}

There has been a considerable disagreement among the researchers about native language influence. As said by Gass and Selinker (1994), changes in the psychological base in SL theories mark the changes in the role of L1. 
Firstly, in terms of transfer theory, it was linked to a particular view of language learning as a series of habits which could be developed only through practice and reinforcement. Errors, then, were believed to result from the L1 interference. In 1970s, under the influence of cognitive approach, numerous empirical studies were conducted to validate the $\mathrm{CAH}$ only to find out that this hypothesis lacks support in its predictive power. The significance of L1 was called into question. Error Analysis emerged to make up for CAH, in which L1 was considered one of some other causes leading to errors. However, it failed to give the whole picture of learner's learning acquisition because it looked only at the errors rather than the other aspects of learner's performance such as avoidance (i.e speakers tried to avoid using them to overcome difficulties or problems that might emerge from it). L1 influence once again fell into the hands of other new SLA theories. The fall of CAH and EA led to two separate phases, which considered the role of L1 in two different ways. Due to the limitations of the scope, this article only deals with the L1's contributions to SLA according to two early approaches - CAH and EA and leave the room discussing how and why the ideas of the role of L1 in L2 acquisition have changed as SLA theories have developed in other articles. Also, L1 transfer on different aspects of L2 acquisition, e.g. relating to spoken and written language, is also recommended for investigating.

\section{References}

Bot, K. de, Lowie, W. \& Verspoor, M. (2006), "Second language acquisition: An advanced resource book", Reprint, New York: Routledge.

Byram, M. (2004), "Routledge encyclopedia of language teaching and learning", New York: Routledge.

Chomsky, N. (1959), "A review of B.F. Skinner's Verbal Behavior", Language, 35, 1, 26-58

Corder, S.P (1967), "The significance of learner's errors", International Review of Applied Linguistics, 9, 147159.

Dulay, H. \& Burt, M (1973), "Should we teach children syntax", Language Learning 23, 245-58

Ellis, R. (1985), "Understanding Second Language Acquisition", Oxford: Oxford University Press.

Ellis, R. (1990), "Instructed second language acquisition", Oxford: Brasil Blackwell Ltd.

Ellis, R. (1994), "The study of second language acquisition", Oxford: Oxford University Press.

Gass, S.M. \& Selinker, L. (1994), "Second language acquisition: An introductory course (ed)", New York and London: Routledge.

Gass, S.M. \& Selinker, L. (2008), "Second language acquisition: An introductory course (3rd. ed)", New York and London: Routledge.

Karim, K. \& Nassaji, H. (2013), "First language transfer in second language writing: An examination of current research", Iranian Journal of Language Teaching Research 1 (1), (Jan, 2013), 117-134.

Larsen-Freeman, D. \& Long, M. H. (1991), "An introduction to second language research", London: Longman. Lightbown, P.M \& Spada, N. (2006), "How languages are learned (ed)", Oxford: Oxford University Press.

Mitchell, R. \& Myles, F (1998), "Second language learning theories (ed)," London: Arnold.

Mitchell, R., Myles, F. \& Marsden, E. (2013), "Second language learning theories (ed)", New York: Routledge.

Odlin, T. (1989), "Language transfer: Cross-linguistic influence in language teaching", Cambridge: Cambridge University Press.

Odlin, T. (2005), "Cross-linguistic influence in Doughty, C. \& Long, .H. (eds)", The handbook of second language acquisition. Oxford: Blackwell Publishing House.

Saville-Troike, M. (2006), "Introducing second language acquisition", Cambridge: Cambridge University Press.

Schachter, J. (1974), "An error in error analysis", Language Learning, 24, 205-214. Oxford, Blackwell

Selinker, L. (1972), "Interlanguage, IRAL", International Review of Applied Linguistics in Language Teaching, 10(3), 209 